\title{
RECENSIÓN
}

\section{EVALUACIÓN DE LAS ACTIVIDADES DE LUCHA CONTRA EL TABACO EXPERIENCIAS Y PRINCIPIOS ORIENTADORES}

\author{
C. Chollat-Traquet \\ Año 1998 \\ Organización Mundial de la Salud. Ginebra. \\ ISBN 92-435-4490-X \\ 227 páginas
}

Recensión: Teresa Robledo de Dios. Jefa del Servicio de Promoción de Hábitos Saludables. Subdirección General de Epidemiología, Promoción y Educación para la Salud. Dirección General de Salud Pública. Ministerio de Sanidad y Consumo.

En esta publicación de la Organización Mundial de la Salud (OMS), se proporcionan los principios generales e instrumentos necesarios para evaluar los programas de salud pública en la lucha antitabáquica.

Para ello, se presenta una selección cuidadosa de las medidas preventivas en este campo, a la vez que se evalúa su pertinencia, eficiencia, eficacia y efecto.

Esta publicación nace como una medida para poder aplicar la resolución WHA43.16, adoptada por la 43. ${ }^{a}$ Asamblea Mundial de la Salud (1990), por la que se pedía al Director General de la OMS que vigilara la marcha y la eficacia de los programas destinados a la lucha contra el uso del tabaco.

El libro consta de cuatro partes, desarrolladas en 19 capítulos. La información metodológica y las recomendaciones contenidas en las partes 1, 2 y 3 incluyen ejemplos seleccionados en función de la variedad de enfoques y técnicas de evaluación que se presentan.

La parte 1 trata de los principios generales para evaluar los programas de lucha contra el tabaco, proporcionando la base gene- ral sobre las cuestiones de «tabaco o salud» y los programas de lucha afines, a la vez que facilita un examen general de los principios y métodos que pueden utilizarse para su evaluación. En el primer capítulo se resumen los elementos esenciales del planteamiento «tabaco o salud» y los motivos para adoptar ciertas normativas.

En los capítulos 2 y 3 se reseñan los principios generales de la evaluación y se examinan los conceptos epidemiológicos y limitaciones prácticas. Así, el capítulo 2 proporciona indicaciones generales sobre la preparación y el calendario de la evaluación, y los procedimientos que han de usarse, mientras que el capítulo 3 trata de los complejos aspectos de la medición de los resultados y el empleo de los mismos.

En la parte 2 se trata la evaluación de las medidas destinadas a proteger a la población general, considerando primero el efecto del tabaco sobre las economías nacionales y la validez del uso de medidas económicas tales como la política de precios, la imposición y los controles de la distribución. Para posteriormente analizar las restricciones basadas en la edad y las medidas para limitar los lugares en donde puede usarse el tabaco. 
El efecto del tabaco en las distintas economías nacionales se evalúa en el capítulo 4 . El capítulo 5 analiza aquellas medidas económicas de control, estudiando la base racional de la imposición y la fijación de precios como medidas de lucha antitabáquica, y describiendo el concepto de elasticidad negativa de los precios respecto a la demanda.

La importancia de legislar sobre concentraciones máximas de nicotina y alquitrán, considerada como destacada medida de salud pública que trata de mejorar el entorno de la comunidad sin requerir cambios conductuales ni acciones individuales, sc recoge en el capítulo 6, así como se plantea la creciente preocupación despertada por los distintos aditivos utilizados para el tratamiento del tabaco.

La eficacia de las medidas tendentes a la reducción de la disponibilidad de tabaco como las restricciones de edad, la prohibición de las ventas de productos de tabaco a menores y la limitación de las ventas en máquinas automáticas..., y el reconocimiento del derecho a respirar aire exento de los efectos nocivos del humo del tabaco, en los lugares y transportes públicos, $\mathrm{y}$ en el lugar de trabajo se desarrolla en los tres siguientes capítulos.

Posteriormente, se habla de la importancia de los centros sanitarios y de la intervención de los profesionales de la salud, dado su papel modélico, educador, social y asistencial en materia de prevención de tabaquismo, así como de la necesidad de las advertencias sobre la salud y de la prohibición de la publicidad y el patrocinio del tabaco.

Mientras que las medidas de protección de la salud pueden lograr que se comuniquen a la población las advertencias primordiales sobre los riesgos del consumo de tabaco y que se ejerza cierto control sobre el tabaquismo, sigue siendo necesaria la información y la educación. Proteger la salud de la población es indispensable, pero no sufi- ciente. La función de la promoción de la salud consiste en impulsar a las personas a que sean responsables de su propia salud.

La promoción de la salud abarca desde las campañas masivas, que facilitan datos sobre el perjuicio del uso del tabaco, a la formación $\mathrm{y}$ la persuasión individuales, que con frecuencia se necesitan, debido el carácter productor de dependencia de la nicotina. Y son estos aspectos de la promoción de la salud, el fomento, la información y la educación los que se describen en la parte 3, en particular la evaluación de la eficacia del uso de los medios informativos, la función de los programas de prevención del uso de tabaco en las escuelas y en la comunidad, la acción del personal sanitario y la función de los programas de cesación del uso de tabaco.

Tanto en la parte $2 .^{a}$ como en la $3 .^{a}$ se presenta, en la medida lo posible, cada tipo de actividad de lucha antitabáquica de un modo normalizado:

Tras una breve definición de lo que puede abarcar la actividad, se facilitan ejemplos de evaluaciones realizadas en distintos contextos nacionales.

Posteriormente, se describen los métodos que han de aplicarse en la evaluación, el tipo de información necesaria y el procedimiento para evaluar la pertinencia, idoneidad, eficiencia, efectividad, avance y efecto de cada actividad.

Por último se establecen indicadores para las evaluaciones.

En la parte 4 se examina el modo de fortalecer las medidas de control mediante disposiciones legislativas apropiadas. Trata del «valor añadido» dado a las medidas de lucha antitabáquica cuando se promulgan por medio de la legislación. Se trata de evaluar la precisión del proceso que conduce a la adopción y aplicación de las medidas legislativas y la efectividad de las propias disposiciones legislativas. 
En definitiva, se trata de una publicación excelente, dirigida a responsables políticos, técnicos de salud pública, y a todos aquellos profesionales, sanitarios o no, del sector público o privado, que trabajan en programas y/o actividades de prevención del tabaquismo, y que necesitan profundizar en el arte de la evaluación, que no es más que dar una opinión justa, basada en el examen cuidadoso y en el análisis crítico de una situación dada. 